\title{
Acute phase segmental radial strain correlates with recovery and late gadolinium extent in ST-elevation myocardial infarction (STEMI): analysis of the abciximab intracoronary versus intravenously drug application in STEMI substudy
}

\author{
Dominik Buckert ${ }^{1}$, Awad Belal ${ }^{1}$, Adrian Seidl ${ }^{1}$, Wolfgang Rottbauer ${ }^{1}$, Holger Thiele $^{2}$, Volker Rasche ${ }^{1}$, \\ Jochen Wöhrle ${ }^{3}$ \\ ${ }^{1}$ Department of Internal Medicine II, University Hospital Ulm, Ulm, Germany; ${ }^{2}$ Heart Center Leipzig at University of Leipzig and Leipzig Heart \\ Institute, Leipzig, Germany; ${ }^{3}$ Department of Cardiology, Medical Campus Lake Constance, Friedrichshafen, Germany
}

Contributions: (I) Conception and design: D Buckert, J Wöhrle; (II) Administrative support: W Rottbauer, V Rasche, J Wöhrle; (III) Provision of study materials or patients: W Rottbauer, H Thiele, J Wöhrle; (IV) Collection and assembly of data: D Buckert, A Belal, A Seidl, V Rasche; (V) Data analysis and interpretation: D Buckert, A Belal, A Seidl; (VI) Manuscript writing: All authors; (VII) Final approval of manuscript: All authors.

Correspondence to: Dominik Buckert, MD. Department of Internal Medicine II, University Hospital Ulm, Albert-Einstein-Allee 23, 89081 Ulm, Germany. Email: dominik.buckert@uni-ulm.de.

Background: The role of regional strain evaluation in patients with acute reperfused ST-elevation myocardial infarction (STEMI) is not well determined. The objective of this study was the description of regional strain characteristics in the acute and chronic phase of myocardial infarction and its correlation with symptom-to-balloon time and final extent of myocardial scar assessed by cardiac magnetic resonance imaging.

Methods: The study cohort has been derived from the randomized controlled Abciximab Intracoronary versus Intravenously Drug Application in STEMI (AIDA STEMI) trial enrolled at the University of Ulm. All patients received comprehensive cardiac magnetic resonance imaging examinations in the acute phase and 6 months later.

Results: There was a significant improvement of all global deformation indices over time (global longitudinal strain: $-13.1 \% \pm 5.1 \%$ to $-15.5 \% \pm 5.8 \%, \mathrm{P}=0.001$; global circumferential strain: $-14.4 \% \pm 3.7 \%$ to $-16.8 \% \pm 3.6 \%, \mathrm{P}<0.0001$; global radial strain: $28.1 \% \pm 8.7 \%$ to $31.9 \% \pm 9.2 \%, \mathrm{P}=0.0002)$. Mean radial strain of ischemic segments significantly improved $(16.6 \% \pm 10.8 \%$ to $23.7 \% \pm 12.8 \%, \mathrm{P}<0.0001)$, while mean radial strain of remote segments remained unchanged $(40.2 \% \pm 9.4 \%$ to $39.4 \% \pm 9.4 \%, P=0.570)$. There was a significant correlation between acute phase radial strain of ischemic segments and either symptom-to-balloon time $(\mathrm{P}=0.013)$, as well as extent of late gadolinium enhancement at follow-up $(\mathrm{P}<0.0001)$. Using a cut-off of $\leq 27 \%$, acute phase radial strain predicted infarction of the corresponding segment with high sensitivity and specificity (74.4\% and $69.0 \%$ respectively, $\mathrm{P}<0.001)$.

Conclusions: Segmental radial strain in the acute phase of infarction showed a significant correlation to either symptom-to-balloon-time and the extent of late gadolinium enhancement at follow-up, thus potentially serving as early surrogate for left ventricular remodeling and outcome in STEMI.

Keywords: Cardiac magnetic resonance (CMR); feature tracking (FT); myocardial infarction; cardiac deformation

Submitted Jan 14, 2021. Accepted for publication Mar 22, 2021.

doi: 10.21037/qims-21-56

View this article at: http://dx.doi.org/10.21037/qims-21-56 


\section{Introduction}

Cardiac magnetic resonance imaging (CMR) represents the reference modality for the assessment of global and regional left ventricular function. Several CMR derived parameters have been shown to exhibit important prognostic information in the setting of acute reperfused ST-elevation myocardial infarction (STEMI), such as infarct size, myocardial salvage index, microvascular obstruction and intramyocardial hemorrhage (1-3).

Since its introduction in 2009, feature tracking (FT) has become an innovative tool in the growing armamentarium of CMR. It allows for the quantitative assessment of deformation characteristics (strain, strain rate, displacement and velocity) on global and regional level. Global indicesespecially global longitudinal strain (GLS) - have been applied in research extensively and could prove their diagnostic and prognostic significance in various structural cardiac diseases, as well as in ischemic heart disease and STEMI (4-8). Regarding regional strain, the available evidence is less conclusive. There is a limited number of studies assessing regional strain (mostly in circumferential and radial orientation) in acute myocardial infarction patients. Results have in part successfully been correlated to other imaging surrogates, such as wall thickening or presence of microvascular obstruction (9-11). Yet, there is no reference standard for regional strain assessment and reporting. Consequently, different imaging sequences and post-processing methods have been used, leading to heterogenous results. The role of regional strain assessment in acute myocardial infarction thus remains unclear.

In our study, patients with acute reperfused STEMI underwent a comprehensive CMR protocol at baseline and follow-up. The objective was the description of regional strain characteristics in the acute and chronic phase of the infarction and the correlation of the results to clinical features and other imaging derived surrogates.

\section{Methods}

\section{Study population}

The study population has been derived from the previously published Abciximab Intracoronary versus Intravenously Drug Application in STEMI (AIDA STEMI) trial (12). In brief, AIDA STEMI was a randomized, open-label, multicenter trial (registration at ClinicalTrials.gov under NCT00712101). We present data from patients enrolled at the University of Ulm between September 2008 and April
2011. Patients presenting with acute STEMI (symptomto-balloon time $<12 \mathrm{~h}$ ) were enrolled and assigned in a 1:1-fashion to intracoronary versus intravenous abciximab bolus during percutaneous coronary intervention. The primary endpoint was the composite of all-cause mortality, recurrent infarction, or new congestive heart failure within 90 days of randomization. Patients with history of myocardial infarction or previous surgical revascularization were excluded. The study was conducted in accordance with the Declaration of Helsinki (as revised in 2013). The study was approved by institutional ethics board of Ulm University (NO.: 15/18) and individual consent for this retrospective analysis was waived.

\section{CMR substudy}

Within the AIDA STEMI trial, a CMR substudy was conducted, consisting of 795 patients enrolled at 8 centers. For the present study, patients recruited at the University of Ulm were retrospectively analyzed. All patients received a comprehensive CMR examination 1 to 10 days after the index event and at follow-up approximately 6 months later. CMR studies were conducted on a $1.5 \mathrm{~T}$ whole-body scanner with dedicated cardiac 32 phased-array receiver coil (Philips, Best, the Netherlands). Details on the CMR protocol have been published earlier (13). It comprised the thorough assessment of right and left ventricular function, mass and volumes, as well as the analysis of tissue characteristics such as myocardial salvage index, infarct size, and presence and extent of microvascular obstruction.

\section{Image analysis}

Validated CMR evaluation software was used for all quantitative analyses including strain assessment $(\mathrm{cmr} 42$ version 5.6.5, Circle Cardiovascular Imaging Inc., Calgary, Alberta, Canada). Regions of infarcted myocardium were detected on short axis images using a semiautomated computer-based threshold approach (14). In principle endocardial and epicardial contours were delineated manually in the $3 \mathrm{D}$ short axis stack. Afterwards, a region of interest was drawn in remote, i.e., non-infarcted myocardium. By using the 5 standard deviation threshold technique, infarcted myocardium was detected automatically by the software. Manual correction was performed where necessary to avoid signal contamination by epicardial adipose tissue. Results were reported as a percentage of left ventricular volume according to the 16-segment model of the American Heart 
Table 1 Baseline characteristics

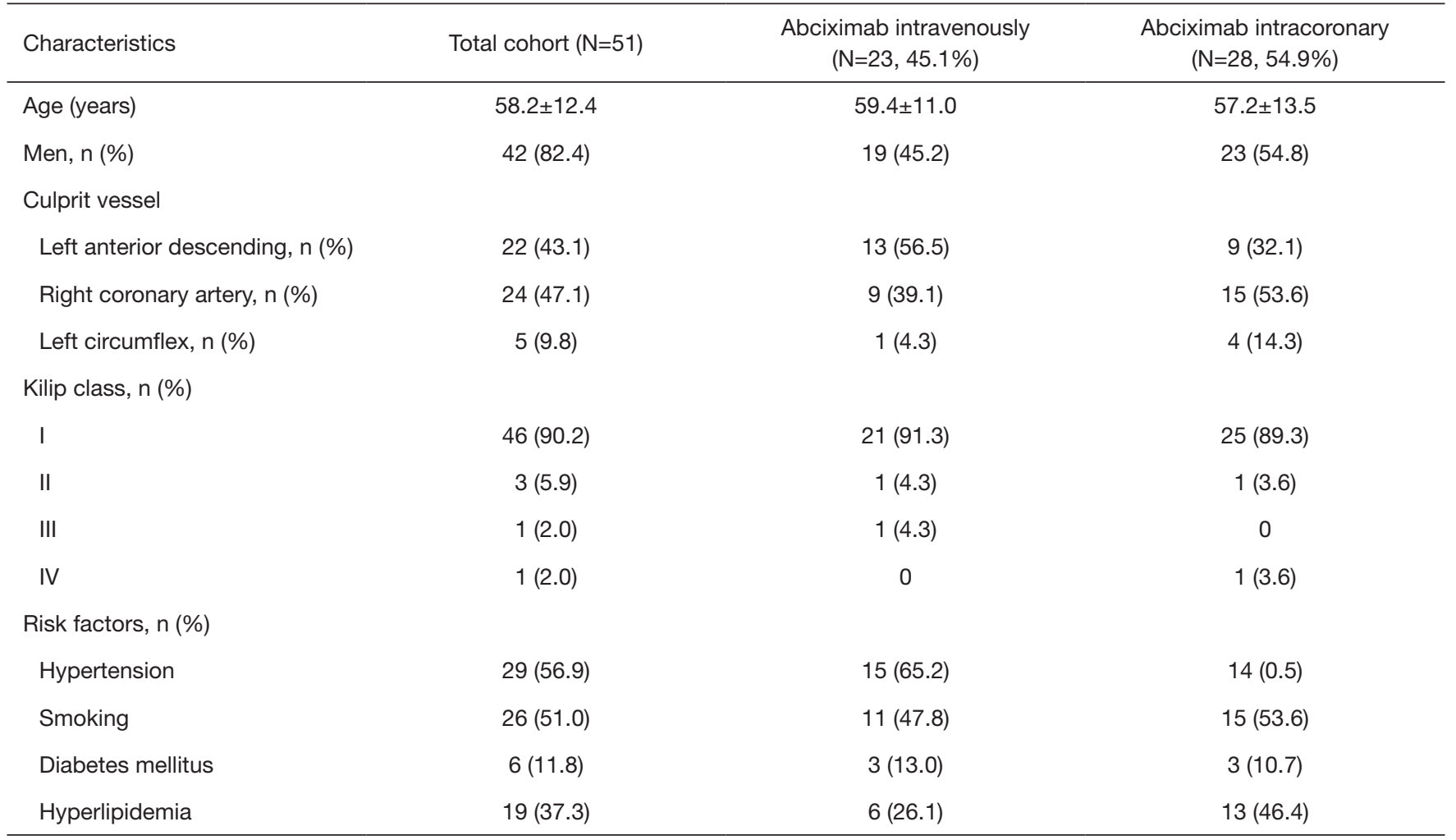

Association (15). Deformation parameters (i.e., strain, strain rate, displacement and velocity) were assessed by manual delineation of endocardial and epicardial contours on shortaxis and corresponding long-axis cine sequences (16). Global indices as well as segmental values were calculated by the software. Papillary muscles were excluded from left ventricular mass, left ventricular outflow tract was excluded from left ventricular volumes. CMR analysis was performed by two experienced readers in consensus in all cases. Interobserver variability varied between 0.90 and 0.98 (intraclass correlation) for the different strain parameters.

\section{Statistical analysis}

Continuous variables were tested for normal distribution by the D'Agostino-Pearson test and reported as mean \pm standard deviation or median with interquartile range $\left(25^{\text {th }}\right.$ $75^{\text {th }}$ percentile), respectively. For comparison, a two-tailed $t$-test was applied in case of normal distribution, otherwise the Mann-Whitney rank sum test was used. Correlation coefficients and regression analyses were calculated to evaluate relationships between continuous variables. A receiver operating characteristics curve analysis was used to calculate the ability of abnormal segmental radial strain to predict relevant myocardial necrosis.

Statistical analysis was performed using commercially available software (MedCalc version 18.11, Mariakerke, Belgium). Overall, a $\mathrm{P}$ value $\leq 0.05$ was judged significant.

\section{Results}

\section{Study population}

The study population consisted of 51 patients. Mean age was $58.2 \pm 12.4$ years, 42 patients were men $(82.4 \%)$. Hypertension was present in $29(56.9 \%)$ subjects, 6 patients had diabetes mellitus (11.8\%). The culprit vessel was found in 22 cases $(43.1 \%)$ to be the left anterior descending (LAD), in 24 cases $(47.1 \%)$ the right coronary artery (RCA) and in 5 patients $(9.8 \%)$ the left circumflex (LCX). Randomization assigned 23 subjects (45.1\%) to the intravenous Abciximab bolus group, 28 patients $(54.9 \%)$ received intracoronary Abciximab. All patients received guideline directed medical therapy. The frequency and distribution of cardiovascular risk factors, as well as clinical baseline characteristics are depicted in Table 1. 
Table 2 Procedural characteristics and clinical outcomes

\begin{tabular}{|c|c|c|c|}
\hline Variable & Total cohort $(\mathrm{N}=51)$ & $\begin{array}{l}\text { Abciximab intravenously } \\
\qquad(\mathrm{N}=23,45.1 \%)\end{array}$ & $\begin{array}{l}\text { Abciximab intracoronary } \\
\qquad(\mathrm{N}=28,54.9 \%)\end{array}$ \\
\hline Symptom-to-balloon time min [median (25-75 percentiles)] & $199(130-279)$ & $220(132-289)$ & $190(130-229)$ \\
\hline Door-to-balloon time min [median (25-75 percentiles)] & $45(35-65)$ & $44(33-66)$ & $46(36-64)$ \\
\hline \multicolumn{4}{|l|}{ TIMI flow after percutaneous intervention, $\mathrm{n}(\%)$} \\
\hline Grade, 1 & $1(2.0)$ & $1(4.3)$ & $0(0)$ \\
\hline Primary endpoint within 12 months of follow-up, $n$ (\%) & $0(0)$ & $0(0)$ & $0(0)$ \\
\hline
\end{tabular}

TIMI, Thrombolysis in Myocardial Infarction.

Table 3 Cardiac magnetic resonance imaging results in acute phase and at follow-up

\begin{tabular}{|c|c|c|c|}
\hline Variable & Acute phase & Follow-up & $\mathrm{P}^{\dagger}$ \\
\hline Left ventricular end-diastolic volume index $\left(\mathrm{mL} / \mathrm{m}^{2}\right)$ & $70.8 \pm 12.8$ & $69.7 \pm 15.3$ & 0.530 \\
\hline Left ventricular ejection fraction (\%) & $43.0 \pm 11.2$ & $46.2 \pm 11.3$ & 0.007 \\
\hline Left ventricular mass (g) & $154.4 \pm 41.6$ & $131.6 \pm 37.0$ & $<0.0001$ \\
\hline Global longitudinal strain (\%) & $-13.1 \pm 5.1$ & $-15.5 \pm 5.8$ & 0.001 \\
\hline Global circumferential strain (\%) & $-14.4 \pm 3.7$ & $-16.8 \pm 3.6$ & $<0.0001$ \\
\hline Global radial strain (\%) & $28.1 \pm 8.7$ & $31.9 \pm 9.2$ & 0.0002 \\
\hline Mean radial strain-ischemic segments (\%) & $16.6 \pm 10.8$ & $23.7 \pm 12.8$ & $<0.0001$ \\
\hline
\end{tabular}

${ }^{\dagger}$, paired samples $t$-test.

\section{Procedural characteristics and follow-up}

Symptom-to-balloon time was $<12 \mathrm{~h}$ in all patients per study inclusion criteria. Median time was 199 min (130279 min). Forty-six patients $(90.2 \%)$ had Thrombolysis in Myocardial Infarction (TIMI) flow grade 3 after percutaneous intervention, 4 patients $(7.8 \%)$ had TIMI flow grade 2 and in one subject (2.0\%), TIMI flow grade 1 could be seen. There were no primary endpoints (composite of all-cause mortality, recurrent infarction, new congestive heart failure) within 12 months of follow-up. Table 2 depicts procedural characteristics and clinical outcomes.

\section{CMR results}

Mean number of days from myocardial infarction to first
CMR were 4.6 \pm 2.3 days. Mean number of days from first to second CMR were $184.1 \pm 12.8$ days. Table 3 shows CMR results in the acute phase and at follow-up. Whereas left ventricular end diastolic volume remained stable $(142.1 \pm 31.7$ vs. $140.7 \pm 33.6 \mathrm{~mL}, \mathrm{P}=0.630)$, left-ventricular mass significantly decreased over time $(154.4 \pm 41.6$ to $131.6 \pm 37.0 \mathrm{~g}$, $\mathrm{P}<0.0001)$. In parallel, there was a significant improvement in left ventricular ejection fraction $(43.0 \% \pm 11.2 \%$ to $46.2 \% \pm 11.3 \%, \mathrm{P}=0.007)$ and global deformation indices (global longitudinal strain: $-13.1 \% \pm 5.1 \%$ to $-15.5 \% \pm 5.8 \%$, $\mathrm{P}=0.001$; global circumferential strain: $-14.4 \% \pm 3.7 \%$ to $-16.8 \% \pm 3.6 \%, \mathrm{P}<0.0001$; global radial strain: $28.1 \% \pm 8.7 \%$ to $31.9 \% \pm 9.2 \%, \mathrm{P}=0.0002)$. Mean radial strain of ischemic segments significantly improved $(16.6 \% \pm 10.8 \%$ to $23.7 \% \pm 12.8 \%, \mathrm{P}<0.0001$ ), while mean radial strain of 
Table 4 Mean radial strain of ischemic and remote segments in dependence of culprit vessel

\begin{tabular}{lcc}
\hline Variable & Acute phase & Follow-up \\
\hline Left anterior descending & & $\mathrm{P}^{\dagger}$ \\
Mean radial strain-ischemic segments (\%) & $16.1 \pm 9.6$ & $25.0 \pm 15.8$ \\
Mean radial strain-remote segments (\%) & $40.7 \pm 8.2$ & $38.3 \pm 9.0$ \\
Left circumflex & & 0.002 \\
Mean radial strain-ischemic segments (\%) & $11.8 \pm 7.1$ & $22.5 \pm 5.0$ \\
Mean radial strain-remote segments (\%) & $36.7 \pm 2.9$ & $34.9 \pm 7.4$ \\
Right coronary artery & & 0.004 \\
Mean radial strain-ischemic segments (\%) & $18.1 \pm 12.3$ & $22.8 \pm 11.1$ \\
Mean radial strain-remote segments (\%) & $40.5 \pm 11.3$ & $41.4 \pm 9.9$ \\
\hline
\end{tabular}

${ }^{\dagger}$, paired samples $t$-test.

remote segments remained unchanged $(40.2 \% \pm 9.4 \%$ to $39.4 \% \pm 9.4 \%, P=0.570)$. Recovery of radial strain could be observed for all culprit vessels, whereas LAD and LCX infarcts showed greater recovery than RCA infarcts (Table 4).

The route of abciximab administration was not associated with differing clinical or CMR parameters, neither at baseline nor at follow-up (Table 5).

Regression analysis revealed a significant correlation between symptom-to-balloon time and mean radial strain of ischemic segments $(\mathrm{P}=0.013$, Figure 1). Moreover, there was a significant correlation between acute phase radial strain and extent of late gadolinium enhancement at follow-up $(\mathrm{P}<0.001$, Figure 2). Using a cut-off criterion of $\leq 27 \%$, acute phase radial strain predicted a relevant infarction (defined as segmental late gadolinium extent $\geq 15 \%$ ) with a sensitivity of $74.4 \%$ and a specificity of $69.0 \%$ (AUC $0.775, \mathrm{P}<0.001$ ). The corresponding receiver operating characteristics curve is depicted in Figure 3.

\section{Discussion}

In this retrospective analysis of acute reperfused STEMI patients, CMR derived myocardial deformation characteristics are described at baseline and follow-up. Radial strain of ischemic segments was significantly reduced in the acute phase of infarction with a substantial recovery for all culprit vessels. Moreover, regional radial strain showed significant correlation to both symptom-to-balloon time and the extent of late gadolinium enhancement at follow-up, thus potentially serving as early surrogate for outcome and remodeling in STEMI patients.
Since its introduction in CMR, a growing number of studies have focused on the potential role of FT derived functional parameters in myocardial infarction. For global indices, especially global longitudinal left ventricular strain, there is a robust evidence base indicating strong prognostic value in this setting. For instance, a prospective observational study consisting of 451 revascularized STEMI patients demonstrated the incremental prognostic power of global longitudinal strain for the prediction of major adverse cardiac events when added to a prognostic model containing conventional risk factors such as left ventricular ejection fraction, infarct size and microvascular obstruction (17).

For regional strain, the situation is far less conclusive. Several studies sought to identify prognostic value of regional strain parameters but a uniform assessment and reporting still is lacking, in part due to relevant intervendor, intercenter and interobserver variabilities $(16,18)$. A major study by Gavara et al. rigorously assessed global and segmental strain parameters in 323 STEMI patients from a large retrospective registry (19). The authors analyzed intraand interobserver variabilities and proposed a reporting system based on AHA's 16 segment model $(19,20)$. In summary, they assessed cut-off values for each segment and strain direction in an external validation cohort. These cut-off values were then used to identify segments with "altered" strain in the study population. Finally, the number of altered segments was analyzed regarding endpoint prediction. Though the number of altered segments in all strain directions was associated with poor outcome, regional strain analysis did not sustain its prognostic value when combined with other potent CMR and clinical predictors. 
Table 5 Comparison of intravenously vs. intracoronary Abciximab bolus administration

\begin{tabular}{|c|c|c|c|}
\hline Variable & Abciximab, intravenous & Abciximab, intracoronary & $\mathrm{P}^{\dagger}$ \\
\hline Left ventricular end-diastolic volume-follow-up (mL) & $135.5 \pm 31.2$ & $145.0 \pm 35.4$ & 0.032 \\
\hline Left ventricular ejection fraction-baseline (\%) & $41.9 \pm 10.6$ & $43.9 \pm 11.8$ & 0.530 \\
\hline Left ventricular ejection fraction-follow-up (\%) & $45.4 \pm 7.0$ & $46.8 \pm 14.0$ & 0.680 \\
\hline Left ventricular mass - follow-up (g) & $124.4 \pm 25.7$ & $137.5 \pm 43.9$ & 0.210 \\
\hline Global longitudinal strain-baseline (\%) & $-12.8 \pm 6.2$ & $-13.4 \pm 4.2$ & 0.680 \\
\hline Global longitudinal strain-follow-up (\%) & $-14.7 \pm 7.4$ & $-16.2 \pm 4.0$ & 0.340 \\
\hline Global circumferential strain-baseline (\%) & $-13.7 \pm 4.1$ & $-15.0 \pm 3.4$ & 0.230 \\
\hline Global radial strain-follow-up (\%) & $31.3 \pm 7.9$ & $32.3 \pm 10.3$ & 0.690 \\
\hline Mean radial strain-ischemic segments-baseline (\%) & $15.1 \pm 10.0$ & $17.8 \pm 11.4$ & 0.370 \\
\hline Mean radial strain-ischemic segments-follow-up (\%) & $23.1 \pm 12.4$ & $24.2 \pm 13.4$ & 0.780 \\
\hline Mean radial strain-remote segments-baseline (\%) & $42.3 \pm 10.3$ & $38.5 \pm 8.5$ & 0.160 \\
\hline Mean radial strain-remote segments-follow-up (\%) & $38.8 \pm 7.7$ & $39.9 \pm 10.6$ & 0.660 \\
\hline Symptom-to-balloon time (min) & $231.0 \pm 110.1$ & $222.5 \pm 126.7$ & 0.800 \\
\hline Door-to-balloon time (min) & $52.8 \pm 28.8$ & $52.2 \pm 24.1$ & 0.950 \\
\hline
\end{tabular}

${ }^{\dagger}$, independent samples $t$-test.

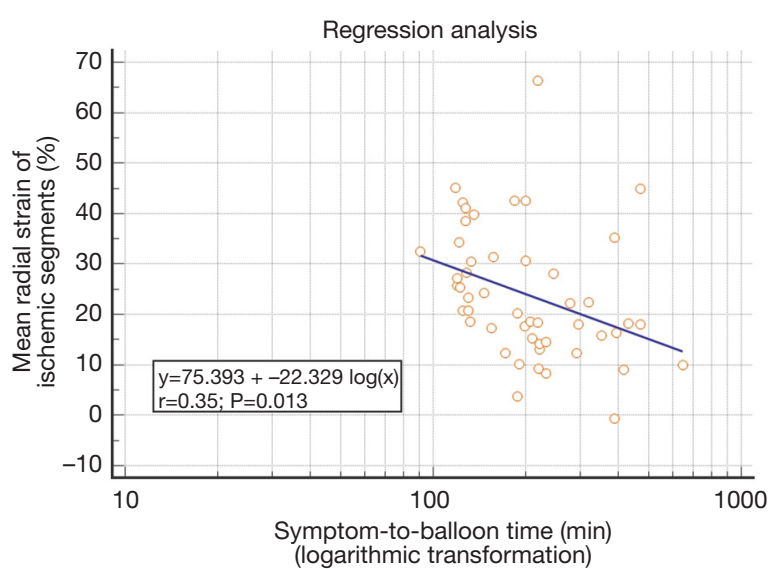

Figure 1 Regression analysis between symptom-to-balloon time and mean radial strain of ischemic segments. Logarithmic transformation of symptom-to-balloon time because of not normal distribution.

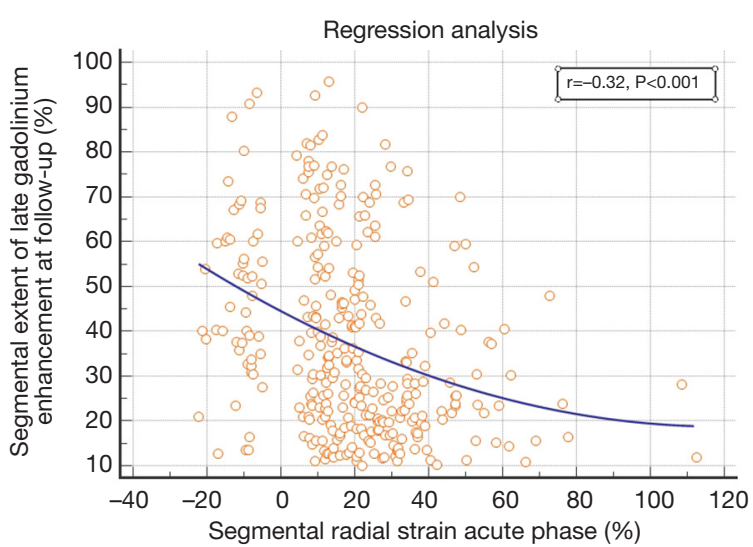

Figure 2 Regression analysis between segmental radial strain in acute phase and segmental extent of late gadolinium enhancement at follow-up. 


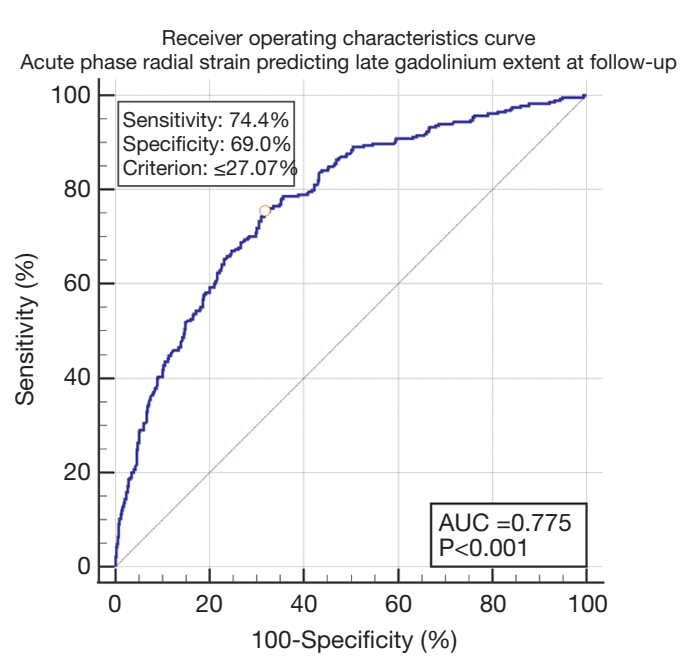

Figure 3 Receiver operating characteristics curve of acute phase radial strain predicting late gadolinium extent at follow-up. AUC, area under the curve.

This finding might be a consequence of insufficient spatial resolution of just 16 myocardial segments, especially regarding segments adjacent to the myocardial infarction with a mixture of damaged and healthy myocardial tissue. In our study, a modified approach was therefore used. By using radial segmental strain as continuous variable, linear correlation to the extent of late gadolinium enhancement at follow-up could be demonstrated. Of note, receiver operating characteristics analysis in our cohort revealed a comparable cut-off for relevantly reduced segmental radial strain $(27 \%)$ as compared to the study former mentioned (32\%) (19). Prognostic value can be assumed but surely has to be examined in a larger and preferably prospective cohort.

Though analysis revealed a significant correlation between radial segmental strain and extent of late gadolinium enhancement at follow-up, a lot of scattering had to be observed. This issue was addressed in recent research comparing the performance of different FT CMR software packages in healthy subjects and patients with myocardial infarction (21). With their findings the authors confirmed the fact that interchangeability between the available vendors is not given and that reproducibility still needs improvement, especially for segmental strain analysis (coefficient of variation ranging from $15 \%$ to $90 \%$ ). Nevertheless, radial segmental strain had the best test metrics so far, especially for the detection of regional left ventricular pathology (21). Our findings, in line with previous research, thus suggest segmental radial strain as preferred functional parameter for the detection and description of infarction related myocardial injury, probably by best reflecting the transmural damage that takes place in this setting $(21,22)$.

\section{Limitations}

The study cohort is too small to evaluate the prognostic impact of segmental radial strain in terms of major adverse cardiac events. In addition, all patients had 6 months follow-up MRI and thus no event was recorded in the study population within 12 months due to selection criteria (patients who experienced a "early" primary endpoint within 6 months after index event who were not able to have the second MRI were intentionally excluded). Furthermore, reproducibility at this point is insufficient, as pointed out before. Moreover, CMR derived strain measurements exhibit lower temporal resolution as compared to echocardiography, thus hindering exchangeability across different imaging modalities. Nevertheless, from a hypothesis generating point of view, our study legitimates further evaluation of this intuitive parameter in prospective STEMI cohorts.

\section{Conclusions}

In conclusion, feasibility of describing regional left ventricular function by FT CMR could be demonstrated. The correlation of segmental radial strain at the time of the infarction with either symptom-to-balloon-time and the extent of myocardial scar/necrosis at follow-up suggests this parameter to be used as early remodeling surrogate and prognostic tool in STEMI. Interchangeability between vendors and reproducibility must be improved substantially to facilitate application in clinical routine.

\section{Acknowledgments}

Funding: None.

\section{Footnote}

Conflicts of Interest: All authors have completed the ICMJE uniform disclosure form (available at http://dx.doi. org/10.21037/qims-21-56). The authors have no conflicts of interest to declare.

Ethical Statement: The authors are accountable for all aspects of the work in ensuring that questions related 
to the accuracy or integrity of any part of the work are appropriately investigated and resolved. The study was conducted in accordance with the Declaration of Helsinki (as revised in 2013). The study was approved by institutional ethics board of Ulm University (NO.: 15/18) and individual consent for this retrospective analysis was waived.

Open Access Statement: This is an Open Access article distributed in accordance with the Creative Commons Attribution-NonCommercial-NoDerivs 4.0 International License (CC BY-NC-ND 4.0), which permits the noncommercial replication and distribution of the article with the strict proviso that no changes or edits are made and the original work is properly cited (including links to both the formal publication through the relevant DOI and the license). See: https://creativecommons.org/licenses/by-nc-nd/4.0/.

\section{References}

1. Eitel I, Desch S, Fuernau G, Hildebrand L, Gutberlet M, Schuler G, Thiele H. Prognostic significance and determinants of myocardial salvage assessed by cardiovascular magnetic resonance in acute reperfused myocardial infarction. J Am Coll Cardiol 2010;55:2470-9.

2. Eitel I, Kubusch K, Strohm O, Desch S, Mikami Y, de Waha S, Gutberlet M, Schuler G, Friedrich M, Thiele H. Prognostic value and determinants of a hypointense infarct core in $\mathrm{T} 2$-weighted cardiac magnetic resonance in acute reperfused ST-elevation myocardial infarction. Circ Cardiovasc Imaging 2011;4:354-62.

3. Wöhrle J, Merkle N, Kunze M, Cristea E, Mehran R, Rottbauer W, Stone G. Effect of bivalirudin compared with unfractionated heparin plus abciximab on infarct size and myocardial recovery after primary percutaneous coronary intervention: the horizons-AMI CMRI substudy. Catheter Cardiovasc Interv 2012;79:1083-9.

4. Schuster A, Hor KN, Kowallick JT, Beerbaum P, Kutty S. Cardiovascular Magnetic Resonance Myocardial Feature Tracking: Concepts and Clinical Applications. Circ Cardiovasc Imaging 2016;9:e004077.

5. Schuster A, Paul M, Bettencourt N, Morton G, Chiribiri A, Ishida M, Hussain S, Jogiya R, Kutty S, Bigalke B, Perera D, Nagel E. Cardiovascular magnetic resonance myocardial feature tracking for quantitative viability assessment in ischemic cardiomyopathy. Int J Cardiol 2013;166:413-20.

6. Buss SJ, Breuninger K, Lehrke S, Voss A, Galuschky C, Lossnitzer D, Andre F, Ehlermann P, Franke J, Taeger T,
Frankenstein L, Steen H, Meder B, Giannitsis E, Katus HA, Korosoglou G. Assessment of myocardial deformation with cardiac magnetic resonance strain imaging improves risk stratification in patients with dilated cardiomyopathy. Eur Heart J Cardiovasc Imaging 2015;16:307-15.

7. Eitel I, Stiermaier T, Lange T, Rommel KP, Koschalka A, Kowallick JT, Lotz J, Kutty S, Gutberlet M, Hasenfuß G, Thiele H, Schuster A. Cardiac Magnetic Resonance Myocardial Feature Tracking for Optimized Prediction of Cardiovascular Events Following Myocardial Infarction. JACC Cardiovasc Imaging 2018;11:1433-44.

8. Buckert D, Cieslik M, Tibi R, Radermacher M, Rasche V, Bernhardt P, Hombach V, Rottbauer W, Wöhrle J. Longitudinal strain assessed by cardiac magnetic resonance correlates to hemodynamic findings in patients with severe aortic stenosis and predicts positive remodeling after transcatheter aortic valve replacement. Clin Res Cardiol 2018;107:20-9.

9. Neizel M, Lossnitzer D, Korosoglou G, Schäufele T, Peykarjou H, Steen H, Ocklenburg C, Giannitsis E, Katus HA, Osman NF. Strain-Encoded MRI for Evaluation of Left Ventricular Function and Transmurality in Acute Myocardial Infarction. Circ Cardiovasc Imaging 2009;2:116-22.

10. Everaars H, Robbers LFHJ, Götte M, Croisille P, Hirsch A, Teunissen PFA, van de Ven PM, van Royen N, Zijlstra F, Piek JJ, van Rossum AC, Nijveldt R. Strain analysis is superior to wall thickening in discriminating between infarcted myocardium with and without microvascular obstruction. Eur Radiol 2018;28:5171-81.

11. Pahlm US, Ubachs JF, Heiberg E, Engblom H, Erlinge D, Götberg M, Arheden H. Regional wall function before and after acute myocardial infarction; an experimental study in pigs. BMC Cardiovasc Disord 2014;14:118.

12. Thiele H, Wöhrle J, Hambrecht R, Rittger H, Birkemeyer R, Lauer B, Neuhaus P, Brosteanu O, Sick P, Wiemer M, Kerber S, Kleinertz K, Eitel I, Desch S, Schuler $\mathrm{G}$. Intracoronary versus intravenous bolus abciximab during primary percutaneous coronary intervention in patients with acute ST-elevation myocardial infarction: a randomized trial. Lancet 2012;379:923-31.

13. Thiele H, Wöhrle J, Neuhaus P, Brosteanu O, Sick P, Prondzinsky R, Birkemeyer R, Wiemer M, Kerber S, Schuehlen H, Kleinertz K, Axthelm C, Zimmermann R, Rittger H, Braun-Dullaeus RC, Lauer B, Burckhardt W, Ferrari M, Bergmann MW, Hambrecht R, Schuler G. Intracoronary compared with intravenous bolus abciximab application during primary percutaneous coronary 
intervention: design and rationale of the Abciximab Intracoronary versus intravenously Drug Application in ST-Elevation Myocardial Infarction (AIDA STEMI) trial. Am Heart J 2010;159:547-54.

14. Kim HW, Farzaneh-Far A, Kim RJ. Cardiovascular magnetic resonance in patients with myocardial infarction: current and emerging applications. J Am Coll Cardiol 2009;55:1-16.

15. Cerqueira MD, Weissman NJ, Dilsizian V, Jacobs AK, Kaul S, Laskey WK, Pennell DJ, Rumberger JA, Ryan T, Verani MS. Standardized Myocardial Segmentation and Nomenclature for Tomographic Imaging of the Heart. Circulation 2002;105:539-42.

16. Pedrizzetti G, Claus P, Kilner PJ, Nagel E. Principles of cardiovascular magnetic resonance feature tracking and echocardiographic speckle tracking for informed clinical use. J Cardiovasc Magn Reson 2016;18:51.

17. Reindl M, Tiller C, Holzknecht M, Lechner I, Beck A, Plappert D, Gorzala M, Pamminger M, Mayr A, Klug G, Bauer A, Metzler B, Reinstadler SJ. Prognostic Implications of Global Longitudinal Strain by FeatureTracking Cardiac Magnetic Resonance in ST-Elevation Myocardial Infarction. Circ Cardiovasc Imaging 2019;12:e009404.

18. Schuster A, Stahnke VC, Unterberg-Buchwald C, Kowallick JT, Lamata P, Steinmetz M, Kutty S, Fasshauer M, Staab W, Sohns JM, Bigalke B, Ritter C, Hasenfuß G, Beerbaum P, Lotz J. Cardiovascular magnetic resonance feature-tracking assessment of myocardial mechanics: Intervendor agreement and considerations regarding

Cite this article as: Buckert D, Belal A, Seidl A, Rottbauer W, Thiele H, Rasche V, Wöhrle J. Acute phase segmental radial strain correlates with recovery and late gadolinium extent in ST-elevation myocardial infarction (STEMI): analysis of the abciximab intracoronary versus intravenously drug application in STEMI substudy. Quant Imaging Med Surg 2021;11(8):35953603. doi: 10.21037/qims-21-56 reproducibility. Clin Radiol 2015;70:989-98.

19. Gavara J, Rodriguez-Palomares JF, Valente F, Monmeneu JV, Lopez-Lereu MP, Bonanad C, Ferreira-Gonzalez I, Garcia Del Blanco B, Rodriguez-Garcia J, Mutuberria M, de Dios E, Rios-Navarro C, Perez-Sole N, Racugno P, Paya A, Minana G, Canoves J, Pellicer M, Lopez-Fornas FJ, Barrabes J, Evangelista A, Nunez J, Chorro FJ, GarciaDorado D, Bodi V. Prognostic Value of Strain by Tissue Tracking Cardiac Magnetic Resonance After ST-Segment Elevation Myocardial Infarction. JACC Cardiovasc Imaging 2018;11:1448-57.

20. Wang N, Hung CL, Shin SH, Claggett B, Skali H, Thune JJ, Køber L, Shah A, McMurray JJ, Pfeffer MA, Solomon SD; VALIANT Investigators. Regional cardiac dysfunction and outcome in patients with left ventricular dysfunction, heart failure, or both after myocardial infarction. Eur Heart J 2016;37:466-72.

21. Dobrovie M, Barreiro-Pérez M, Curione D, Symons R, Claus P, Voigt JU, Bogaert J. Inter-vendor reproducibility and accuracy of segmental left ventricular strain measurements using CMR feature tracking. Inter-vendor reproducibility and accuracy of segmental left ventricular strain measurements using CMR feature tracking. Eur Radiol 2019;29:6846-57.

22. Mirea O, Pagourelias ED, Duchenne J, Bogaert J, Thomas JD, Badano LP, Voigt JU; EACVI-ASE-Industry Standardization Task Force. Intervendor Differences in the Accuracy of Detecting Regional Functional Abnormalities: A Report From the EACVI-ASE Strain Standardization Task Force. JACC Cardiovasc Imaging 2018;11:25-34. 